\title{
Endogenous Neurostimulation and Physiotherapy in Cluster Headache: A Clinical Case
}

\author{
Gonzalo Navarro-Fernández ${ }^{1,2}$, Lucía de-la-Puente-Ranea ${ }^{1}$, Marisa Gandía-González ${ }^{3}$ \\ and Alfonso Gil-Martínez 1,2,4,*iD \\ 1 Departamento de Fisioterapia, Centro Superior de Estudios Universitarios La Salle, Universidad Autónoma \\ de Madrid, Madrid 28023, Spain; gonza_navarro93@hotmail.com (G.N.-F.); \\ luciadelapuenteranea@gmail.com (L.d.-l.-P.-R.) \\ 2 Motion in Brains Research Group, Instituto de Neurociencias y Ciencias del Movimiento, Centro Superior de \\ Estudios Universitarios La Salle, Universidad Autónoma de Madrid, Madrid 28023, Spain \\ 3 Servicio de Neurocirugía, Hospital Universitario La Paz, Madrid 28046, Spain; marisagg4@hotmail.com \\ 4 Hospital La Paz Institute for Health Research, Madrid 28046, Spain \\ * Correspondence: fongilmar@gmail.com
}

Received: 15 February 2019; Accepted: 8 March 2019; Published: 12 March 2019

\begin{abstract}
Objective: The aim of this paper is to describe the progressive changes of chronic cluster headaches $(\mathrm{CHs})$ in a patient who is being treated by a multimodal approach, using pharmacology, neurostimulation and physiotherapy. Subject: A male patient, 42 years of age was diagnosed with left-sided refractory chronic $\mathrm{CH}$ by a neurologist in November 2009. In June 2014, the patient underwent a surgical intervention in which a bilateral occipital nerve neurostimulator was implanted as a treatment for headache. Methods: Case report. Results: Primary findings included a decreased frequency of $\mathrm{CH}$ which lasted up to 2 months and sometimes even without pain. Besides this, there were decreased levels of anxiety, helplessness (PCS subscale) and a decreased impact of headache (HIT-6 scale). Bilateral pressure pain thresholds (PPTs) were improved along with an increase in strength and motor control of the neck muscles. These improvements were present at the conclusion of the treatment and maintained up to 4 months after the treatment. Conclusions: A multimodal approach, including pharmacology, neurostimulation and physiotherapy may be beneficial for patients with chronic CHs. Further studies such as case series and clinical trials are needed to confirm these results.
\end{abstract}

Keywords: cluster headache; neurosurgery; pressure pain threshold; physiotherapy

\section{Introduction}

The cluster headache $(\mathrm{CH})$ has been defined by the International Headache Society as the most frequent trigeminal autonomic headache [1]. $\mathrm{CHs}$ is reported to be found in $0.12 \%$ of the population, with an overall male-to-female ratio of 3:1; episodic $\mathrm{CH}$ is more common than chronic $\mathrm{CH}[2,3]$. $\mathrm{CHs}$ are characterized by severe unilateral pain in short-duration episodes, which are associated with ipsilateral autonomic symptoms which primarily encompass the temporal, supraorbital and infraorbital areas [1,3].

Much research performed in the early 2000s confirmed the involvement of the changes in the hypothalamus in patients with $\mathrm{CH}$. For instance, May et al. concluded that there were activation and structural changes in the gray matter of the posterior and inferior parts of the hypothalamus [4]. More recent studies have also shown that there is hypothalamus activation in patients with $\mathrm{CH}$, but there are no structural changes in the gray matter in that area, unlike other regions in which morphological changes were found, such as the hippocampus, anterior insula, orbitofrontal cortex, 
cerebellum, temporal lobe, anterior cingulate cortex and the primary and secondary somatosensory cortex [5]. The convergence theory describes the anatomo-functional convergence of the cervical (especially C2), somatic trigeminal and dural trigeminovascular afferent neurons on second-order nociceptors in the trigeminocervical complex [6]. One of the supporting studies found limited duration, frequency and intensity of cluster attacks after blockades, asserting the theory of convergence [7-9].

These findings could, therefore, be related to the extensive effect of pharmacological treatments proposed for patients with $\mathrm{CH}$, such as sumatriptan, [3,10,11] other triptans, [12,13] verapamil, [13] lithium, [3,13] oxygen therapy, [14] onabotulinumtoxinA [15] and alternative treatments such as valproic acid, topiramate and methylprednisone [13].

The American Headache Society only proposes pharmacological and oxygen therapy as acute treatment with " $\mathrm{A}$ " level recommendation [16]. The lack of evidence makes the inclusion of other therapies in the evidence-based treatment guidelines more difficult. Moreover, the review of the effects of the principal drugs used in the treatment of acute $\mathrm{CH}$ shows side effects such as chest pain, paresthesia, dizziness, tingling feeling or numbness of the limbs, heaviness, asthenia, nausea, unpleasant taste, and somnolence $[17,18]$. Somatostatin treatment also has some side effects, and the most frequent among them are hyperglycaemia, nausea, abdomianal pain, diarrhea, and meteorism [18]. Adverse effects are also present in prophylactic treatments. Lithium carbonate produces tremor, gastrointestinal disturbances, dizziness, olfactory disorders and polyuria in $\mathrm{CH}$ patients [18-20]. Even though verapamil has been considered as the first-line prophylactic drug for the treatment of $\mathrm{CH}$ patients with " $\mathrm{A}$ " level recommendation [13], it should be used carefully, because verapramil treatment is noted to have a correlation with the electrocardiographic abnormalities (19\% arrhythmias and $36 \%$ of bradycardia incidence) [21].

Limitations of drug treatment are advised in both episodic and chronic $\mathrm{CH}$ because $10 \%$ to $20 \%$ of CCHs have the chance of becoming drug-resistant headaches [22], and a new line in the research has been opened to increase the use of non-pharmacological adjuvant treatments for $\mathrm{CH}$.

There are some non-invasive stimulation methods that have been used in $\mathrm{CH}$ patients. At first, the results obtained by Nesbitt et al. in 2015 suggested that non-invasive vagal nerve stimulation can be used as both acute and prophylactic treatment in ECH and CCH [23]. However, it has recently been shown that non-invasive vagal nerve stimulation is an effective treatment in $\mathrm{ECH}$ when compared with sham stimulation, but not in the $\mathrm{CCH}$ patient group [24]. Additionally, some investigators are assessing the effects obtained by using transcranial magnetic stimulation techniques in $\mathrm{CH}[25,26]$, but the evidence is still limited [27].

One of the most investigated invasive stimulation methods is sphenopalatine ganglion stimulation (SPG). This method was used in a study published in 2017, and it was concluded that after 24 months, $45 \%$ of the patients with refractory $\mathrm{CCH}$ were acute responders and $35 \%$ were frequent responders. Even though $81 \%$ of the side effect incidences were reported, they noted that SPG produced $61 \%$ of therapeutic responses and should be considered as an interesting treatment for refractory $\mathrm{CCH}$ [28]. Another invasive stimulation method commonly used in $\mathrm{CH}$ patients is occipital nerve stimulation (ONS).Although it has shown that ONS can reduce the frequency and intensity of headache at least by a $50 \%$ in about $60 \%$ of the patients [29], there is a lack of randomized controlled trials of ONS for the treatment of $\mathrm{CH}$ [27].

Moreover, manual therapies are being investigated in other primary headache cases; studies have shown that manual therapy was significantly better in the control group in reducing the intensity and frequency of headache [30].

Our aim was to describe the management of chronic $\mathrm{CH}$ in a patient who is treated by a multimodal approach including pharmacology, neurostimulation and physiotherapy.

\section{Methods}

The CARE (case reporting guideline development) checklist was used to prepare this case report and to complete it to improve quality reports in clinical cases [31]. 


\subsection{Patient}

A male patient of 42 years of age was diagnosed with left-sided refractory chronic $\mathrm{CH}$ by a neurologist in November 2009. The following pharmacological treatment was prescribed by the neurologist: (1) preventive treatment: verapamil $(80 \mathrm{mg})$, topiramate $(100 \mathrm{mg})$, escitalopram (15 mg), clonazepam (0.5 mg), lithium (100 mg) and prednisone (25 mg); and (2) abortive treatment: subcutaneous sumatriptan injection $(6 \mathrm{mg}$ ) and 100\% oxygen. The patient reported loss of memory and concentration as an adverse effect of the medication. In June 2014, the patient underwent a surgical intervention in which a bilateral occipital nerve neurostimulator was implanted as the treatment method for headache.

\subsection{Neurostimulator Implantation Procedure}

To establish a subcutaneous stimulation of the greater occipital nerve complex, the implantation of bilateral 8-contact occipital lead was performed, using anatomical and radiological landmarks.

Surgery was performed with the patient lying in the prone position and completely awake. Under local anesthesia, a midline incision in the back of the neck was made with a small epifascial scalpel. Guided by an anteroposterior X-ray image, a subcutaneous needle followed the curvature of the skin from the $\mathrm{C} 1-\mathrm{C} 2$ transition to the mastoid process on one side, avoiding the perforation of the fascia to prevent subfascial electrode localization on the other side.

The electrodes were placed subcutaneously and the needles were removed. The electrodes were anchored in the fascia after checking the correct coverage of the target area, and then two loops were placed. The electrodes were tunneled to the subcutaneous point at the halfway point between the midline neck incision and the subcutaneous gluteal buttock (on the right or left side, depending on the patient's preference), where the another set of loops lay, which were attached to each electrode and then connected with the extensions (Figure 1). To identified the greater occipital nerve complex correctly, some serial ultrasound images and videos published by Chang KV et al. were used [32].

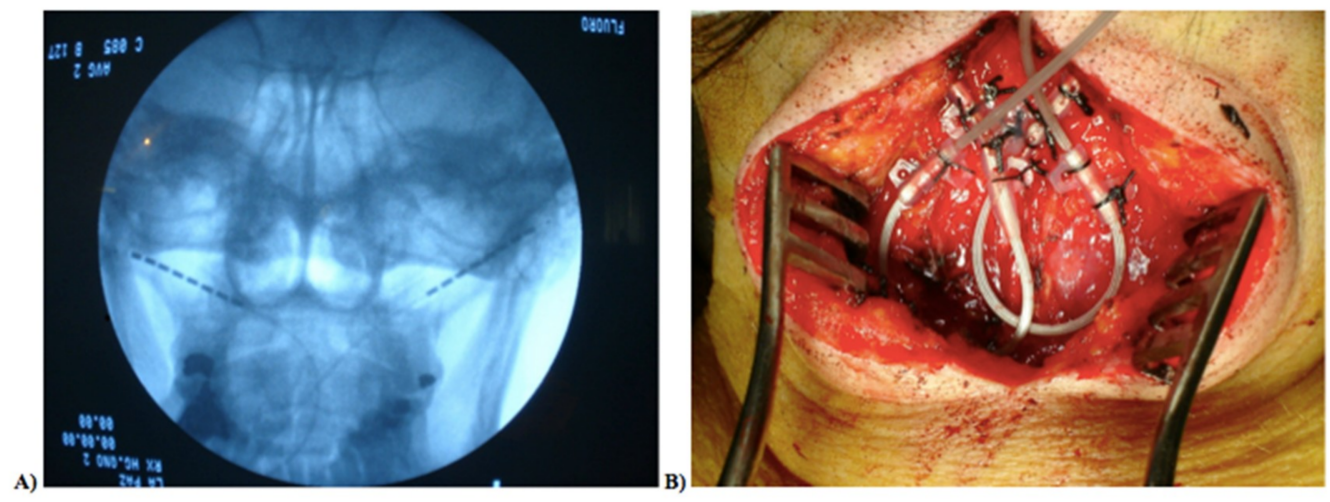

Figure 1. (A) Anteroposterior X-ray electrode image, after removing the needles, prepared for stimulation; (B) fascia anchor in suboccipital level.

The extensions were tunneled to the subcutaneous gluteal buttock, where the implantable pulse generator was definitively placed after the extensions were connected and the correct impedances and stimulation were verified. Incision closure was performed when the correct hemostasis had occurred.

\subsection{Evaluation}

After signing the informed consent, the patient was evaluated before the treatment procedure, after the treatment, and at the 3rd month and 4th month after the treatment. A blinded experienced evaluator assessed both physical and psychological variables, which were selected according to previous observational studies in patients with $\mathrm{CH}$ [33]. Physical variables were pressure pain thresholds (PPTs) assessed bilaterally in the cranial and extracranial areas with a digital algometer [34] 
(Fx. 25 Force Gage, Wagner Instruments, Greenwich, CT, USA); two-point discrimination was tested in the trigeminal areas with an esthesiometer [35]; and cervical flexor endurance was measured with a craniocervical flexion test [36]. Psychological variables were as follows: impact of headache on the quality of life and work performance (HIT-6 scale) [37], pain catastrophizing (PC Scale) [38], neck disability (neck disability Index) [39] and depression symptoms (Hamilton depression rating scale) [40]. At each assessment, we measured the impact and outcome of disease in the patient's daily life (with a verbal numeric rating scale) [41], the intensity and frequency of pain, crisis duration and medication used in each episode, and all the data were recorded in a diary.

After observing the values obtained in the first assessment session, such as the reduced endurance of deep flexor cervical muscles (Table 1), the authors decided to include physical therapy as an adjuvant treatment for the patients.

Table 1. Data and \% of change of physical variables and psychological characteristics.

\begin{tabular}{lccccc}
\hline & Pre & Post & 3 Months & 4 Months & \% of Change \\
\hline PPT & & & & & \% Pre-4 months \\
V1 right & 1.12 & 0.75 & 1.71 & 1.49 & $33.03 \%$ \\
V2 right & 1.62 & 1.22 & 2.45 & 2.77 & $70.98 \%$ \\
V3 right & 1.39 & 0.94 & 2.5 & 1.67 & $20.14 \%$ \\
Temporalis M1 right & 2.58 & 2.13 & 4.17 & 2.73 & $5.81 \%$ \\
Temporalis M2 right & 3.28 & 3.19 & 5.7 & 5.16 & $57.32 \%$ \\
V1 left & 0.72 & 0.62 & 1.52 & 1.29 & $79.17 \%$ \\
V2 left & 1.27 & 1.08 & 2.86 & 3.1 & $144.09 \%$ \\
V3 left & 1.37 & 0.88 & 3.03 & 2.41 & $75.91 \%$ \\
Temporalis M1 left & 1.69 & 2.09 & 3.28 & 3.56 & $110.65 \%$ \\
Temporalis M2 left & 2.85 & 3.19 & 5.35 & 4.64 & $62.81 \%$ \\
Mastoid P right & 3.54 & 3.34 & 4.54 & 4.64 & $31.07 \%$ \\
Mastoid P left & 2.81 & 2.14 & 3.52 & 4.2 & $49.47 \%$ \\
Greater occipital N right & 4.75 & 3.8 & 4.68 & 4.04 & $-14.95 \%$ \\
Greater occipital N left & 4.34 & 3.26 & 4.64 & 3.42 & $-21.20 \%$ \\
Tibialis M right & 4.98 & 6.31 & 17.6 & 10.96 & $120.08 \%$ \\
Tibialis M left & 5.84 & 5.17 & 17.08 & 12.68 & $117.12 \%$ \\
Craniocervical flexion test & & & & & \\
time (s) & 3.06 & 8.22 & 12.47 & 24.06 & - \\
Fatigue & 21.5 & 22 & 43 & 60.5 & - \\
\hline
\end{tabular}

Physiological characteristic
differences Pre-4 months

$\begin{array}{lccccc}\text { HIT-6 } & 63 & 61 & 50 & 54 & -9 \\ \text { NDI } & 18 & 12 & 13 & 13 & -5 \\ \text { PCS } & 17 & 10 & 10 & 10 & -7 \\ \text { PCS rumination } & 8 & 7 & 7 & 7 & -1 \\ \text { PCS magnification } & 0 & 0 & 0 & 0 & 0 \\ \text { PCS helplessness } & 9 & 3 & 3 & 3 & -6 \\ \text { HDRS } & 20 & 18 & 14 & 14 & -6\end{array}$

PPT = pressure pain threshold; $\mathrm{M}=$ muscle; $\mathrm{N}=$ nerve; $\mathrm{P}=$ process; $\mathrm{HIT}-6=$ headache impact test; $\mathrm{NDI}=$ neck disability index; PCS = pain catastrophizing scale; HDRS = Hamilton depression rating scale.

\subsection{Postsurgical Physiotherapy Approach}

The patient received 8 physical therapy sessions in 6 weeks. Manual therapy techniques consisted of passive mobilization of the anterior-posterior upper cervical region, which can directly influence the upper three cervical segments (C0-C3), and three sets of 2 minutes of mobilization were performed with $0.5 \mathrm{~Hz}$ frequency and 30 seconds of rest [42]; additionally, the neurodynamic mobilization of the trigeminal nerve was performed, with 30 repetitions with $0.5 \mathrm{~Hz}$ frequency $(10$ global mobilizations of mandibular opening and 10 mobilizations on each side of the mandibular laterotrusion to ease the tension to the auriculotemporal nerve) (Figure 2A,B). Finally, home exercises were prescribed to 
improve the motor control of deep flexor muscles, as described by Harris et al., [43], and the patient was advised to perform three sets of 10-20 repetitions including 5-10 seconds of contraction with 5-10 seconds of relaxation, depending on the patient's strength.

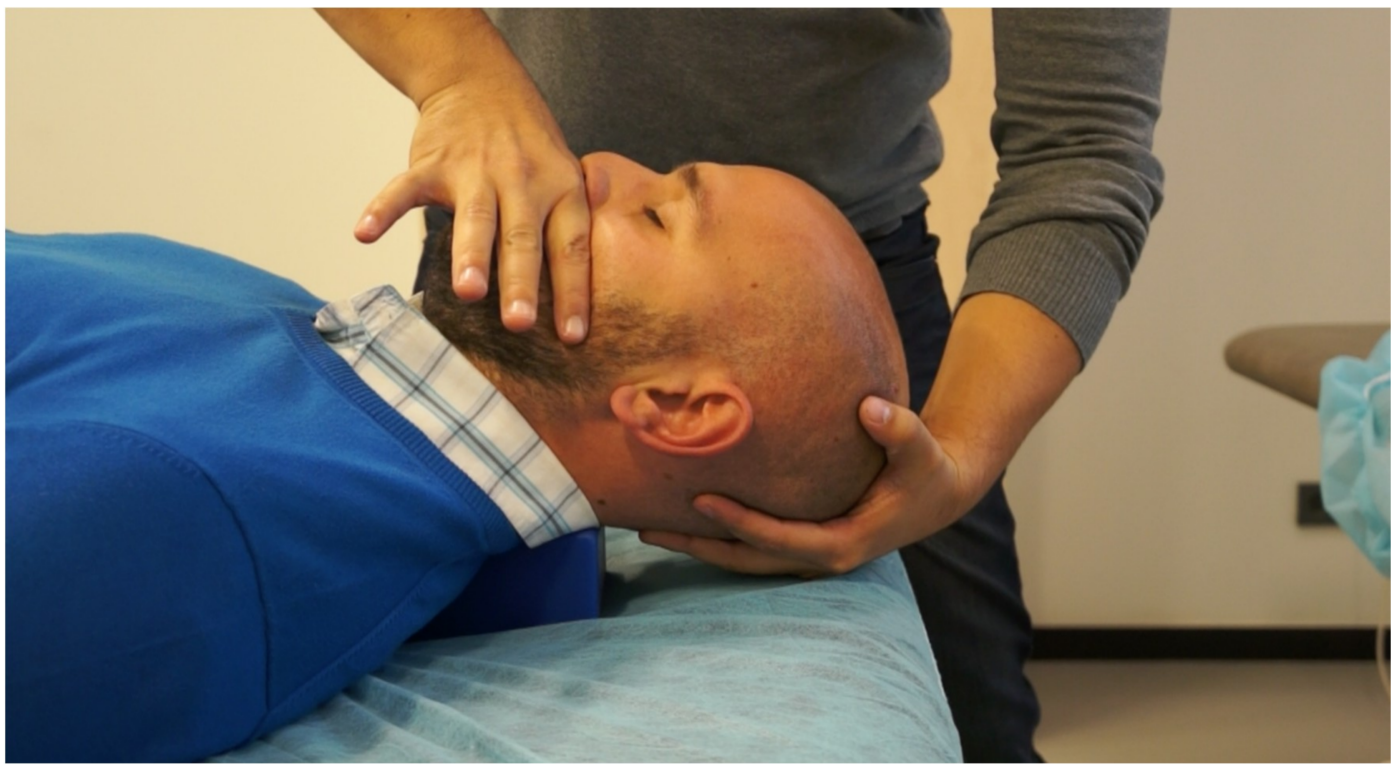

(A)

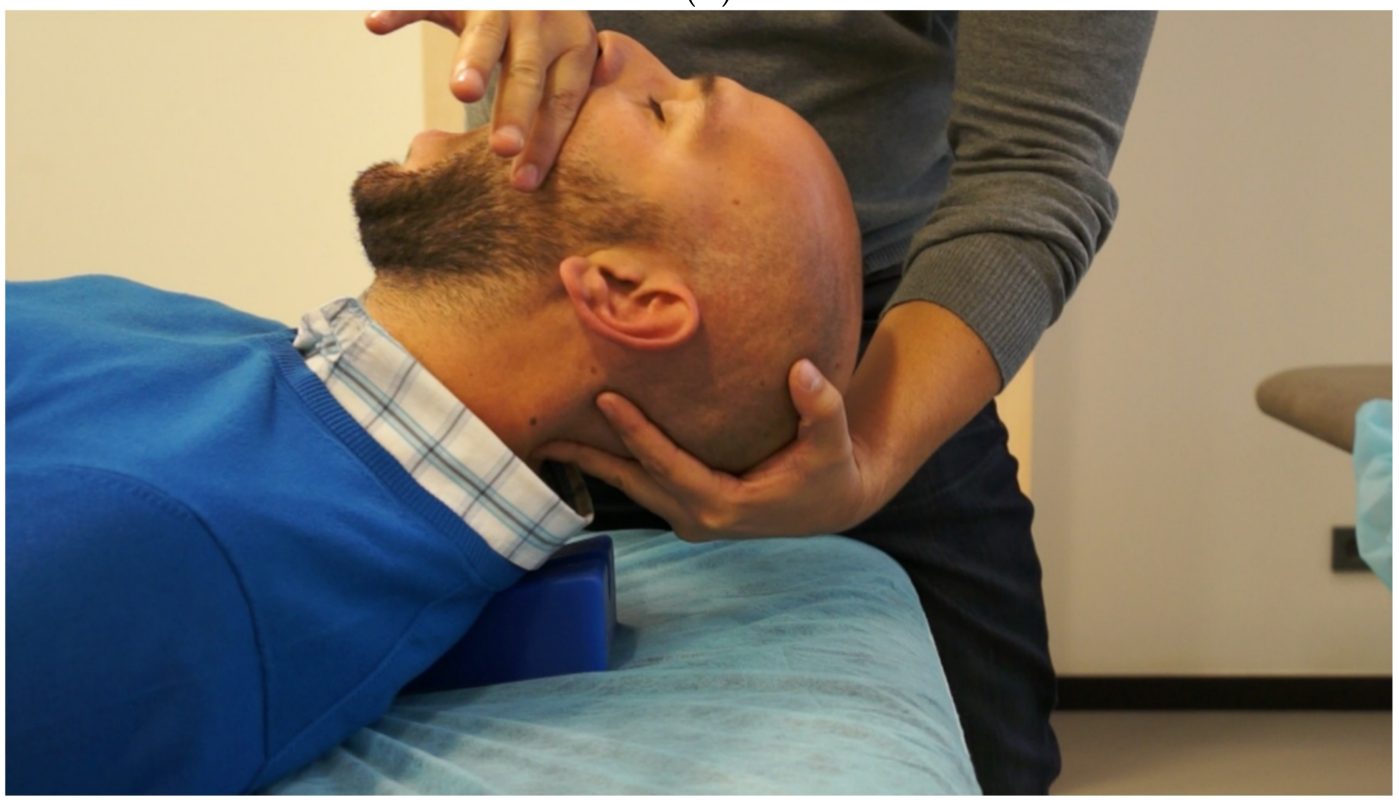

(B)

Figure 2. (A) Neural mobilization (step 1). Craniocervical flexion; (B) neural mobilization (step 2). Craniocervical extension plus mouth opening.

\section{Results and Discussion}

This is the first case to be reported to receive treatment as a combination of neurostimulation and physiotherapy approaches for chronic $\mathrm{CH}$. After analyzing the patient's case diary of headache, a decreased frequency of $\mathrm{CH}$ attacks was observed at the end of treatment, and the progress was maintained even 4 months after the treatment; additionally, it was reported that for the first 2 months there was no pain at all (Table 2). These results could support the use of a multimodal approach as an adjunctive treatment for occipital nerve neurostimulation (C2-C3). The benefits obtained with neurostimulation treatment might support the trigeminal-cervical convergence hypothesis $[44,45]$, 
according to which craniofacial pain is generated by the activation of second-order neurons from the trigeminal nucleus caudalis, [45] a mechanism generated both in animals and in humans. [46] Other authors have developed studies in which it was observed that stimulation of the superior sagittal sinus, innervated by the ophthalmic branch of the trigeminus, also take part in the stimulation of second-order neurons of the trigeminal nucleus caudalis and the dorsal horn of $\mathrm{C} 2-\mathrm{C} 3$. Thus, this supports the trigeminal-cervical convergence hypothesis and provides the basis for neurostimulation.

Table 2. Evolution of headache diary.

\begin{tabular}{ccccc}
\hline Months & Frequency & Intensity & Duration & Abortive Treatment \\
\hline May & 2 & 9 & 25 & SS-OT \\
June & 3 & 9.33 & 23.33 & SS \\
July & 7 & 9.71 & 31.43 & SS-OT \\
August & 2 & 9.50 & 35 & SS \\
September & 0 & - & - & - \\
October & 0 & - & - & - \\
November & 4 & 8.50 & 33.75 & SS-OT \\
\hline
\end{tabular}

SS = subcutaneous sumaptriptan; OT = oxygen therapy.

In addition, physical therapy techniques such as manual therapy, therapeutic exercise or a combination of both, specifically applied in the upper cervical region, had already caused a decrease in the frequency and intensity of various primary headaches. [47-49] These results reinforce our hypothesis that the combination of these techniques might reduce headache frequency due to the activation or inhibition of sensory input from the trigeminal-cervical system [46] in chronic $\mathrm{CH}$.

The decrease in frequency of attacks after the multimodal program can lead to decreased levels of anxiety, helplessness (PCS subscale) and impact of headache (Table 1). Ruscheweyh et al. demonstrated that the frequency of a primary headache is associated with pain-specific disability, quality of life, anxiety and depression, which are significantly more pronounced in patients with a chronic headache than in patients who have episodic attacks [50].

Moreover, the patient showed an improvement (increase) in most PPTs bilaterally, except in those that were examined and assessed on the greater occipital nerve (Table 1). These results could be due to the analgesic effect generated by the joint mobilization [42,51] or trigeminal neural mobilization, [52] along with the pharmacological and neurostimulation treatments. However, the decrease in the occipital nerve PPT coincides with the area of neurostimulator implantation, where the patient had reported a feeling of numbness (paresthesia) [44] that increased while performing a passive lateral glide of $\mathrm{C} 0-\mathrm{C} 1$, which suggests that active and passive craniocervical flexion could generate allodynia at these points, as occurs in $\mathrm{CH}$ conditions [53].

Finally, the inclusion of a therapeutic exercise program could also cause an increase in the strength and motor control of the cervical muscle, which was proved by comparing the pretreatment assessment and the assessment at the fourth month after the treatment (Table 1), which is supported by the evidence of the fact that stabilization exercise is effective in reducing pain [54] and might be useful in the treatment of other primary headaches as well [55]. Instead of longer follow-up, it is better to make the patient aware of the fact that the combination of neurostimulation and physiotherapy could be effective in reducing the frequency, duration, and severity of the $\mathrm{CH}$. This may remove their lack of adherence to the treatment.

Finally, the limitation should be marked that, currently, ultrasound is widely used in assessing neuromuscular disorders. Some headaches could result from the chronic affection of the para-spinal and sub-occipital muscles, which can be easily checked by using ultrasound [32]. Unfortunately, the authors did not use this to examine possible musculoskeletal painful origins in this single case.

In conclusion, a multimodal approach, including pharmacology, neurostimulation and physiotherapy, could be beneficial in the management of patients with chronic $\mathrm{CH}$. 
Author Contributions: Conceptualization, G.N.-F., L.d.-1.-P.-R. and A.G.-M.; methodology, A.G.-M.; software, A.G.-M.; formal analysis, G.N.-F., L.d.-1.-P.-R. and A.G.-M.; investigation, G.N.-F., L.d.-1.-P.-R., M.G.-G. and A.G.-M.; resources, G.N.-F. and L.d.-1.-P.-R.; data curation, G.N.-F. and L.d.-1.-P.-R.; writing-original draft preparation, G.N.-F. and L.d.-1.-P.-R.; writing-review and editing, M.G.-G. and A.G.-M.; visualization, A.G.-M.; supervision, A.G.-M.; project administration, A.G.-M.

Funding: This research received no external funding.

Conflicts of Interest: The authors declare no conflict of interest.

Clinical Implications: Most of the current treatments available for patients with a cluster headache are unsatisfactory. This is the first study that reports the benefits of a multimodal approach, which could be a promising line of research for this complex problem of patients. Further studies, such as case series and clinical trials, are needed to confirm these results.

\section{References}

1. Headache Classification Committee of the International Headache Society (IHS). The International Classification of Headache Disorders, 3rd edition (beta version). Cephalalgia 2013, 33, 629-808. [CrossRef]

2. Fischera, M.; Marziniak, M.; Gralow, I.; Evers, S. The incidence and prevalence of cluster headache: A meta-analysis of population-based studies. Cephalalgia 2008, 28, 614-618. [CrossRef]

3. Meyers, S.L. Cluster headache and trigeminal autonomic cephalgias. Dis. Mon. 2015, 61, 236-239. [CrossRef]

4. May, A.; Bahra, A.; Büchel, C.; Frackowiak, R.S.; Goadsby, P.J. PET and MRA findings in cluster headache and MRA in experimental pain. Neurology 2000, 55, 1328-1335. [CrossRef]

5. Naegel, S.; Holle, D.; Desmarattes, N.; Theysohn, N.; Diener, H.-C.; Katsarava, Z.; Obermann, M. Cortical plasticity in episodic and chronic cluster headache. Neuroimage Clin. 2014, 6, 415-423. [CrossRef] [PubMed]

6. Bartsch, T.; Goadsby, P.J. Stimulation of the greater occipital nerve induces increased central excitability of dural afferent input. Brain 2002, 125, 1496-1509. [CrossRef] [PubMed]

7. Afridi, S.K.; Shields, K.G.; Bhola, R.; Goadsby, P.J. Greater occipital nerve injection in primary headache syndromes-prolonged effects from a single injection. Pain 2006, 122, 126-129. [CrossRef] [PubMed]

8. Ambrosini, A.; Vandenheede, M.; Rossi, P.; Aloj, F.; Sauli, E.; Pierelli, F.; Schoenen, J. Suboccipital injection with a mixture of rapid- and long-acting steroids in cluster headache: A double-blind placebo-controlled study. Pain 2005, 118, 92-96. [CrossRef] [PubMed]

9. Peres, M.F.P.; Stiles, M.A.; Siow, H.C.; Rozen, T.D.; Young, W.B.; Silberstein, S.D. Greater occipital nerve blockade for cluster headache. Cephalalgia 2002, 22, 520-522. [CrossRef]

10. Leone, M.; Proietti Cecchini, A. Long-term use of daily sumatriptan injections in severe drug-resistant chronic cluster headache. Neurology 2015, 86, 194-195. [CrossRef]

11. Ekbom, K.; Monstad, I.; Prusinski, A.; Cole, J.A.; Pilgrim, A.J.; Noronha, D. Subcutaneous sumatriptan in the acute treatment of cluster headache: A dose comparison study. The Sumatriptan Cluster Headache Study Group. Acta Neurol. Scand. 1993, 88, 63-69. [CrossRef] [PubMed]

12. Law, S.; Derry, S.; Moore, R.A. Triptans for acute cluster headache. Cochrane Database Syst. Rev. 2013, 7, CD008042. [CrossRef] [PubMed]

13. May, A.; Leone, M.; Afra, J.; Linde, M.; Sándor, P.S.; Evers, S.; Goadsby, P.J. EFNS guidelines on the treatment of cluster headache and other trigeminal-autonomic cephalalgias. Eur. J. Neurol. 2006, 13, 1066-1077. [CrossRef] [PubMed]

14. Petersen, A.S.; Barloese, M.C.; Jensen, R.H. Oxygen treatment of cluster headache: A review. Cephalalgia 2014, 34, 1079-1087. [CrossRef]

15. Bratbak, D.F.; Nordgård, S.; Stovner, L.J.; Linde, M.; Folvik, M.; Bugten, V.; Tronvik, E. Pilot study of sphenopalatine injection of onabotulinumtoxinA for the treatment of intractable chronic cluster headache. Cephalalgia 2015, 36, 503-509. [CrossRef] [PubMed]

16. Robbins, M.S.; Starling, A.J.; Pringsheim, T.M.; Becker, W.J.; Schwedt, T.J. Treatment of Cluster Headache: The American Headache Society Evidence-Based Guidelines. Headache J. Head Face Pain 2016, 56, 1093-1106. [CrossRef] [PubMed]

17. Gregor, N.; Schlesiger, C.; Akova-Ozturk, E.; Kraemer, C.; Husstedt, I.-W.; Evers, S. Treatment of Cluster Headache Attacks With Less Than 6 mg Subcutaneous Sumatriptan. Headache J. Head Face Pain 2005, 45, 1069-1072. [CrossRef] [PubMed] 
18. Costa, A.; Antonaci, F.; Ramusino, M.C.; Nappi, G. The Neuropharmacology of Cluster Headache and other Trigeminal Autonomic Cephalalgias. Curr. Neuropharmacol. 2015, 13, 304-323. [CrossRef]

19. Savoldi, F.; Bono, G.; Manzoni, G.C.; Micieli, G.; Lanfranchi, M.; Nappi, G. Lithium salts in cluster headache treatment. Cephalalgia 1983, 3, 79-84. [CrossRef] [PubMed]

20. Bussone, G.; Leone, M.; Peccarisi, C.; Micieli, G.; Granella, F.; Magri, M.; Manzoni, G.C.; Nappi, G. Double blind comparison of lithium and verapamil in cluster headache prophylaxis. Headache 1990, 30, 411-417. [CrossRef]

21. Cohen, A.S.; Matharu, M.S.; Goadsby, P.J. Electrocardiographic abnormalities in patients with cluster headache on verapamil therapy. Neurology 2007, 69, 668-675. [CrossRef]

22. Leone, M.; Franzini, A.; Proietti Cecchini, A.; Mea, E.; Broggi, G.; Bussone, G. Costs of hypothalamic stimulation in chronic drug-resistant cluster headache: Preliminary data. Neurol. Sci. 2009, 30, 43-47. [CrossRef]

23. Nesbitt, A.D.; Marin, J.C.A.; Tompkins, E.; Ruttledge, M.H.; Goadsby, P.J. Initial use of a novel noninvasive vagus nerve stimulator for cluster headache treatment. Neurology 2015, 84, 1249-1253. [CrossRef]

24. Goadsby, P.J.; de Coo, I.F.; Silver, N.; Tyagi, A.; Ahmed, F.; Gaul, C.; Jensen, R.H.; Diener, H.-C.; Solbach, K.; Straube, A.; et al. Non-invasive vagus nerve stimulation for the acute treatment of episodic and chronic cluster headache: A randomized, double-blind, sham-controlled ACT2 study. Cephalalgia 2017, 38, 959-969. [CrossRef]

25. Cosentino, G.; Brighina, F.; Brancato, S.; Valentino, F.; Indovino, S.; Fierro, B. Transcranial magnetic stimulation reveals cortical hyperexcitability in episodic cluster headache. J. Pain 2015, 16, 53-59. [CrossRef]

26. Hodaj, H.; Alibeu, J.-P.; Payen, J.-F.; Lefaucheur, J.-P. Treatment of Chronic Facial Pain Including Cluster Headache by Repetitive Transcranial Magnetic Stimulation of the Motor Cortex with Maintenance Sessions: A Naturalistic Study. Brain Stimul. 2015, 8, 801-807. [CrossRef]

27. Schwedt, T.J.; Vargas, B. Neurostimulation for Treatment of Migraine and Cluster Headache. Pain Med. 2015, 16, 1827-1834. [CrossRef]

28. Jürgens, T.P.; Barloese, M.; May, A.; Láinez, J.M.; Schoenen, J.; Gaul, C.; Goodman, A.M.; Caparso, A.; Jensen, R.H. Long-term effectiveness of sphenopalatine ganglion stimulation for cluster headache. Cephalalgia 2017, 37, 423-434. [CrossRef]

29. Magis, D.; Schoenen, J. Advances and challenges in neurostimulation for headaches. Lancet. Neurol. 2012, 11, 708-719. [CrossRef]

30. Chaibi, A.; Russell, M.B. Manual therapies for cervicogenic headache: A systematic review. J. Headache Pain 2012, 13, 351-359. [CrossRef]

31. Gagnier, J.J.; Kienle, G.; Altman, D.G.; Moher, D.; Sox, H.; Riley, D. CARE Group the CARE guidelines: Consensus-based clinical case report guideline development. J. Clin. Epidemiol. 2014, 67, 46-51. [CrossRef] [PubMed]

32. Chang, K.-V.; Lin, C.-P.; Hung, C.-Y.; Özçakar, L.; Wang, T.-G.; Chen, W.-S. Sonographic Nerve Tracking in the Cervical Region: A Pictorial Essay and Video Demonstration. Am. J. Phys. Med. Rehabil. 2016, 95, 862-870. [CrossRef]

33. Fernández-de-las-Peñas, C.; Ortega-Santiago, R.; Cuadrado, M.L.; López-de-Silanes, C.; Pareja, J.A. Bilateral Widespread Mechanical Pain Hypersensitivity as Sign of Central Sensitization in Patients with Cluster Headache. Headache J. Head Face Pain 2011, 51, 384-391. [CrossRef]

34. Kinser, A.M.; Sands, W.A.; Stone, M.H. Reliability and validity of a pressure algometer. J. Strength Cond. Res. 2009, 23, 312-314. [CrossRef] [PubMed]

35. Bulut, T.; Akgun, U.; Ozcan, C.; Unver, B.; Sener, M. Inter- and intra-tester reliability of sensibility testing in digital nerve repair. J. Hand Surg. Eur. 2015, 41, 621-623. [CrossRef]

36. Olson, L.E.; Millar, A.L.; Dunker, J.; Hicks, J.; Glanz, D. Reliability of a clinical test for deep cervical flexor endurance. J. Manip. Physiol. Ther. 2006, 29, 134-138. [CrossRef]

37. Sauro, K.M.; Rose, M.S.; Becker, W.J.; Christie, S.N.; Giammarco, R.; Mackie, G.F.; Eloff, A.G.; Gawel, M.J. HIT-6 and MIDAS as measures of headache disability in a headache referral population. Headache 2010, 50, 383-395. [CrossRef] [PubMed]

38. Olmedilla Zafra, A.; Ortega Toro, E.; Cano, L.A. Validation of the Pain Catastrophizing Scale in Spanish athletes. Cuadernos Psicologia Deporte 2013, 13, 83-93. [CrossRef] 
39. Andrade Ortega, J.A.; Delgado Martínez, A.D.; Almécija Ruiz, R. Validation of the Spanish version of the Neck Disability Index. Spine 2010, 35, E114-E118. [CrossRef] [PubMed]

40. Lobo, A.; Chamorro, L.; Luque, A.; Dal-Ré, R.; Badia, X.; Baró, E. Validation of the Spanish versions of the Montgomery-Asberg depression and Hamilton anxiety rating scales. Med. Clin. 2002, 118, 493-499. [CrossRef]

41. Holdgate, A.; Asha, S.; Craig, J.; Thompson, J. Comparison of a verbal numeric rating scale with the visual analogue scale for the measurement of acute pain. Emerg. Med. 2003, 15, 441-446. [CrossRef]

42. La Touche, R.; París-Alemany, A.; Mannheimer, J.S.; Angulo-Díaz-Parreño, S.; Bishop, M.D.; Lopéz-Valverde-Centeno, A.; von Piekartz, H.; Fernández-Carnero, J. Does mobilization of the upper cervical spine affect pain sensitivity and autonomic nervous system function in patients with cervico-craniofacial pain?: A randomized-controlled trial. Clin. J. Pain 2013, 29, 205-215. [CrossRef]

43. Harris, K.D.; Heer, D.M.; Roy, T.C.; Santos, D.M.; Whitman, J.M.; Wainner, R.S. Reliability of a measurement of neck flexor muscle endurance. Phys Ther. 2005, 85, 1349-1355.

44. Rodrigo, M.D.; Quero, J.; Cía, P.; Escartín, R.; Acín, P.; Bono, C.; Polo, C. Estimulación eléctrica invasiva de C2-C3 en el tratamiento del dolor cefálico y facial: Neuralgia occipital. Migraña transformada. Cefalea en racimos. Algias faciales. Rev. De La Soc. Española Del Dolor 2008, 15, 382-391.

45. Pedersen, J.L.; Barloese, M.; Jensen, R.H. Neurostimulation in cluster headache: A review of current progress. Cephalalgia 2013, 33, 1179-1193. [CrossRef]

46. Piovesan, E.J.; Kowacs, P.A.; Tatsui, C.E.; Lange, M.C.; Ribas, L.C.; Werneck, L.C. Referred pain after painful stimulation of the greater occipital nerve in humans: Evidence of convergence of cervical afferences on trigeminal nuclei. Cephalalgia 2001, 21, 107-109. [CrossRef]

47. Busch, V.; Gaul, C. Exercise in migraine therapy is there any evidence for efficacy? A critical review. Headache 2008, 48, 890-899. [CrossRef]

48. Hall, T.; Chan, H.T.; Christensen, L.; Odenthal, B.; Wells, C.; Robinson, K. Efficacy of a C1-C2 self-sustained natural apophyseal glide (SNAG) in the management of cervicogenic headache. J. Orthop. Sports Phys. Ther. 2007, 37, 100-107. [CrossRef]

49. Skyba, D.A.; Radhakrishnan, R.; Rohlwing, J.J.; Wright, A.; Sluka, K.A. Joint manipulation reduces hyperalgesia by activation of monoamine receptors but not opioid or GABA receptors in the spinal cord. Pain 2003, 106, 159-168. [CrossRef]

50. Ruscheweyh, R.; Müller, M.; Blum, B.; Straube, A. Correlation of headache frequency and psychosocial impairment in migraine: A cross-sectional study. Headache 2014, 54, 861-871. [CrossRef]

51. Chaibi, A.; Russell, M.B. Manual therapies for primary chronic headaches: A systematic review of randomized controlled trials. J. Headache Pain 2014, 15, 67. [CrossRef]

52. Santos, F.M.; Silva, J.T.; Giardini, A.C.; Rocha, P.A.; Achermann, A.P.P.; Alves, A.S.; Britto, L.R.G.; Chacur, M. Neural mobilization reverses behavioral and cellular changes that characterize neuropathic pain in rats. Mol. Pain 2012, 8, 57. [CrossRef] [PubMed]

53. Wilbrink, L.A.; Louter, M.A.; Teernstra, O.P.M.; van Zwet, E.W.; Huygen, F.J.P.M.; Haan, J.; Ferrari, M.D.; Terwindt, G.M. Allodynia in cluster headache. Pain 2017, 158, 1113-1117. [CrossRef]

54. Ferreira, P.H.; Ferreira, M.L.; Maher, C.G.; Herbert, R.D.; Refshauge, K. Specific stabilisation exercise for spinal and pelvic pain: A systematic review. Aust. J. Physiother. 2006, 52, 79-88. [CrossRef]

55. Gil-Martínez, A.; Kindelan-Calvo, P.; Agudo-Carmona, D.; Muñoz-Plata, R.; López-de-Uralde-Villanueva, I.; La Touche, R. Therapeutic exercise as treatment for migraine and tension-type headaches: A systematic review of randomised clinical trials. Rev. Neurol. 2013, 57, 433-443.

(C) 2019 by the authors. Licensee MDPI, Basel, Switzerland. This article is an open access article distributed under the terms and conditions of the Creative Commons Attribution (CC BY) license (http://creativecommons.org/licenses/by/4.0/). 